\title{
Investigation of Relationship between Sociodemographic Factors and HIV Counseling and Testing (HCT) among Young People in Nigeria
}

\author{
Adaeze Oguegbu \\ Department of Health Sciences, Kaplan University, Florida, USA \\ Email: aoguegbu@kaplan.edu
}

Received 19 February 2016; accepted 19 March 2016; published 22 March 2016

Copyright (C) 2016 by author and Scientific Research Publishing Inc. This work is licensed under the Creative Commons Attribution International License (CC BY). http://creativecommons.org/licenses/by/4.0/

(c) (i) Open Access

\section{Abstract}

The main purpose of this study was to examine the association between sociodemographic factors (gender, place of residence, level of education, geopolitical zone, and socioeconomic status) and HCT uptake among young people in Nigeria. The study is a quantitative research guided by one research question and one hypothesis. The target population comprised young people in Nigeria ages 15 to 24 years because the focus of this study was to identify the factors affecting HCT uptake among young people in this age cohort. The representative sample was obtained from the updated master sample frame of rural and urban zones developed by the National Population Commission in Nigeria. This master sample frame was a national survey that comprises all 36 states in Nigeria. Probability sampling technique was used to obtain a sample of 10,091 respondents (ages 15 to 24 years) for the study. The multistage cluster sampling was used to select suitable young people with known probability. Data were collected throughout Nigeria between September and December 2012 from 32,543 households (rural = 22,192; urban = 10,351) using structured and semistructured questionnaires. The individual questionnaires asked about household characteristics, background characteristics of the respondents. Data were analyzed by inputting them into SPSS v21.0 for analysis and then coded them for each participant. The data were summed using descriptive statistics. Frequencies and percentages; measures of central tendencies were used to answer the research question while nonparametric test such as chi-square was used to analyze non-normally distributed data at 0.5 level of significance. Results of data analysis indicated that the sociodemographic variables of gender, place of residence, level of education, geopolitical zone, and SES were significantly associated with HCT uptake. Among others, it was recommended that examining the efficacy of HCT treatments in Nigeria, along with conducting a demographic analysis of the at-risk population, could be beneficial in informing the authorities who are responsible for allocating finite medical resources. 


\section{Keywords}

\section{Gender, Place of Residence, Educational Level, Geopolitical Zone and Socio-Economic Status, Sociodemographic Factors, HIV Counseling}

\section{Introduction}

HIV and AIDS constitute a major global health problem. Many people globally have lost their lives due to HIV and AIDS attacks. In Nigeria for instance, HIV and AIDS stand out as the greatest threat to human life because there is no drug for its cure. As a result of non availability of drugs that can cure the sickness, most of them feel depressed and dejected. The incidence rate of HIV for young people aged 15 to 24 years in Nigeria was approximately 5.6\% in 2012 [1]. The prevalence of HIV among young people in Nigeria can be attributed in part to factors associated with the lack of uptake of HCT [2].

In response to the rising incidence of HIV infection among young people in Nigeria, Obidoa, M'Lan, \& Schensul noted that public health research has begun to focus on identifying the sociodemographic factors affecting the sexual risk behavior of young people [3]. They concluded that the sexual risk among young people in Nigeria is determined by personal, relational, family-based, organizational, and ethnic-based factors. Obidoa et al. also found that sociodemographic factors can affect the sexual risk of young people in Nigeria, including low level of education, rural location, lower socio-economic status (SES), and younger age. Forty-two of 51 of the women who specified that they had sex for the first time in the same year that Obidoa et al. conducted their study were between the ages of 15 and 19 years $(p \leq 0.0001)$. Important factors that influence the uptake of HCT are awareness of HCT $(p<0.001)$, educational status $(p<0.006)$, and knowledge of ART benefits $(p<0.01)$ [4].

Gender, SES, cultural factors, and age are vital factors constituting such susceptibility and that awareness of the risks of and knowledge about HIV do not essentially translate to positive behavioral change [5]. Level of education can play a significant role in HCT uptake among young people [6]. Results from similar studies have revealed that young people with secondary education are approximately 1.8 times more likely to use HCT services than colleagues with just a primary education or no education [7]-[9].

Based upon the review of relevant literature, several sociodemographic factors that affect HCT uptake among young people were identified. The researcher examined the sociodemographic factors affecting HCT uptake among young people in Nigeria. Literature was used to identify independent variables (IVs), such as gender, place of residence, level of education, geopolitical zone, and SES and their relationship with HCT uptake among young people in Nigeria.

Level of education was the highest level of education attained by the respondent; the responses ranged from none to college degree [10]. Geopolitical zone referred to the zones in Nigeria; all economic, political, and educational resources often are shared across the zones [11]. Place of residence referred to where the participants lived or resided [12]. Sex referred to the biological and physiological characteristics defining men and women [13].

SES was an estimate from the participants of how much money in Nigerian Naira (national currency) they made annually [14]. These variables were considered categorical because the participants were classified based upon which categories they belonged to. The researcher assigned referential values to the categories to aid in the data analysis. Gender was categorized as male or female; place of residence was identified as rural or urban; level of education was never attended school, Quranic only, primary, secondary, or higher; geopolitical zone was northcentral, northeast, northwest, southeast, south, or southwest. The purpose of this quantitative study was to determine the association between sociodemographic factors (gender, place of residence, level of education, geopolitical zone, and SES) and HCT uptake among young people ages 15 to 24 years in Nigeria. This study highlighted the need for public health researchers to identify the factors affecting the uptake of HCT among young people because eliminating barriers to HCT uptake could promote HIV prevention efforts in Nigeria [15]. This study is motivated by the need to examine the association between sociodemographic factors (gender, place of residence, level of education, geopolitical zone, and SES) and HCT uptake.

\subsection{Research Question}

RQ1: What is the association between sociodemographic factors (gender, place of residence, level of education, 
geopolitical zone, and SES) and HCT uptake among young people in Nigeria?

\subsection{Hypothesis}

$H_{01}$ : Sociodemographic factors will not be significantly associated with HCT uptake among young people in Nigeria.

$H_{\mathrm{a} 1}$ : Sociodemographic factors will be significantly associated with HCT uptake among young people in Nigeria.

\subsection{Research Methodology}

This study is a quantitative research. Quantitative research is deductive and confirmatory [16]. The design used in the study was a non-experimental, cross-sectional research design. This design was adopted because the data were collected only once in 2013. Again, the use of secondary data made a cross-sectional design the most appropriate for this study.

The target population comprised young people in Nigeria ages 15 to 24 years because the focus of this study was to identify the factors affecting HCT uptake among young people in this age cohort. This age group was considered because according to the NARHS Plus individuals aged 15 to 24 years are considered young adults [14]. The representative sample was obtained from the updated master sample frame of rural and urban zones developed by the National Population Commission in Nigeria. This master sample frame was a national survey that comprises all 36 states in Nigeria [14]. Probability sampling technique was used to obtain a sample of 10091 respondents (ages 15 to 24 years) for the study. The multistage cluster sampling was used to select suitable young people with known probability. Stage 1 involved the selection of rural and urban zones. Stage 2 involved the selection of enumeration areas within the selected rural and urban zones. The listing and selection of households were conducted in Stage 3, and Stage 4 involved the selection of young respondents to complete the survey and participate in HIV testing. Data were collected throughout Nigeria between September and December 2012 from 32,543 households (rural = 22,192; urban = 10,351) using structured and semi-structured questionnaires. The individual questionnaires asked about household characteristics, background characteristics of the respondents. Out of the households, a total of 31,235 individual respondents were interviewed using the NARHS Plus [14]. Among the individual respondents, 15,596 were men, and 15,639 were women, resulting in a response rate of $88 \%$. The data set was released in December 2013 by the FMOH, but it is not yet available to the public. Secondary data were collected from 31,235 respondents who were interviewed using the NARHS Plus [14]. To obtain the required sample size, which comprised young people in Nigeria ages 15 to 24 years, data were filtered to include only individuals in that age range (10,091 individuals).

Data were analyzed by inputting them into SPSS v21.0 for analysis and then coded them for each participant. The data were summed using descriptive statistics. Frequencies and percentages; measures of central tendencies such as the mean, standard deviation, and range were used to answer the research question. Nonparametric test such as chi-square was used to analyze non-normally distributed data.

\section{Results}

\subsection{Research Question}

SES was computed as a construct of the responses to three questions: type of dwelling structure, items currently possessed in household, and number of meals a day throughout an average month. The highest score for SES was 10 , which was converted into a categorical variable (0 - 2: poorest, 3 - 4: poorer, 5 - 6: middle, 7 - 8: richer, 9 - 10: richest). The researcher assigned scores according to the responses of the participants. For type of dwelling structure, a score of 1 was assigned to participants who lived in mud house with thatched roof, mud house with zinc roof, and wood and makeshift structures. A score of 2 was assigned to participants who lived in mini-flats, room and parlor, or single rooms. A score of 3 was assigned to participants who lived in singlefamily house, duplexes, and two- or three-bedroom apartments.

For the items currently possessed in the households, participants were asked whether they owned a total of 22 items, one of which was excluded (owns boat/ship/canoe) because of the vagueness of the statement. A score of 1 was assigned to participants who owned no more than seven items; a score of 2 was assigned to participants who owned more than seven, but not more than 14, items; and a score of 3 was assigned to participants who 
owned more than 14 items. For the number of meals per day throughout an average month, scores were assigned according to the responses: 1 : cannot guarantee one meal a day throughout the month, 2: only afford one meal a day throughout the month, 3: only afford two meals a day throughout the month, and 4: afford three meals a day throughout the month. The highest possible score for SES was 10 (i.e., the sum of the total correct scores), and the lowest was 0 .

Sociodemographic factors comprised five variables: gender, place of residence, level of education, geopolitical zone, and SES. Table 1 presents the frequency table for gender, with the sample comprising 4075 (45.7\%) male participants and 4845 (54.3\%) female participants.

Place of residence was categorized as living in urban or rural areas. A total of 2841 (31.8\%) participants lived in urban areas, and 6079 (68.2\%) participants lived in rural areas of Nigeria (see Table 2).

Level of education was categorized as no formal education, Qur'anic only, primary, secondary, or higher. Eight (0.1\%) participants failed or chose not to respond to education level and these responses were treated as missing responses. For the sample, 1180 (13.2\%) participants had no formal education, 500 (5.6\%) had Qur'anic only, 936 (10.5\%) had primary schooling as their highest level of education, 5572 (62.5\%) had secondary education as their highest level, and 724 (8.1\%) had higher education (see Table 3).

Geopolitical zone of Nigeria was categorized as northcentral, northeast, northwest, southeast, south south, and southwest. The participants were somewhat evenly distributed across the six geopolitical zones, with 1641 (18.4\%) from the northcentral zone, 1345 (15.1\%) from the northeast zone, 1534 (17.2\%) from the northwest zone, 1443 (16.2\%) from the southeast zone, 1631 (18.3\%) from the south south zone, and 1326 (14.9\%) from the southwest zone (see Table 4).

SES was categorized as poorest, poorer, middle, richer, and richest. As observed, 20 (0.2\%) participants belonged to the poorest category, 353 (4\%) belonged to the poorer category, 2765 (31\%) belonged to the middle category, 4337 (48.6\%) belonged to the richer category, and 1444 (16.2\%) belonged to the richest category (see Table 5). There was one observation that had a missing response on SES.

\begin{tabular}{ccc|}
\hline Table 1. Frequency table for gender. & & \\
\hline Gender of participants & Frequency & $\%$ \\
\hline Male & 4075 & 45.7 \\
Female & 4845 & 54.3 \\
Total & 8920 & 100.0 \\
\hline
\end{tabular}

Table 2. Frequency table for place of residence.

\begin{tabular}{ccc}
\hline Place of residence & Frequency & $\%$ \\
\hline Urban & 2841 & 31.8 \\
Rural & 6079 & 68.2 \\
Total & 8920 & 100.0 \\
\hline
\end{tabular}

Table 3. Frequency table for level of education.

\begin{tabular}{ccc}
\hline Level of education & Frequency & $\%$ \\
\hline No formal education & 1180 & 13.2 \\
Qur'anic only & 500 & 5.6 \\
Primary & 936 & 10.5 \\
Secondary & 5572 & 62.5 \\
Higher & 724 & 8.1 \\
Total & 8912 & 99.9 \\
Missing & 8 & 0.1 \\
Total & 8920 & 100.0 \\
\hline
\end{tabular}


Table 4. Frequency table for geopolitical zone.

\begin{tabular}{ccc}
\hline Geopolitical zone & Frequency & $\%$ \\
\hline Northcentral & 1641 & 18.4 \\
Northeast & 1345 & 15.1 \\
Northwest & 1534 & 17.2 \\
Southeast & 1443 & 16.2 \\
Southsouth & 1631 & 18.3 \\
Southwest & 1326 & 14.9 \\
Total & 8920 & 100.0 \\
\hline
\end{tabular}

Table 5. Frequency table for SES.

\begin{tabular}{ccc}
\hline SES & Frequency & $\%$ \\
\hline Poorest & 20 & 0.2 \\
Poorer & 353 & 4.0 \\
Middle & 2765 & 31.0 \\
Richer & 4337 & 48.6 \\
Richest & 1444 & 16.2 \\
Total & 8919 & 100.0 \\
Missing & 1 & 0.0 \\
Total & 8920 & 100.0 \\
\hline
\end{tabular}

\subsection{Hypothesis}

The hypothesis examined whether five sociodemographic factors (gender, place of residence, level of education, geopolitical zone, and SES) were significantly associated with the uptake of HCT among young people in Nigeria.

To examine the association between geopolitical zone and HCT uptake, I conducted a chi-square test between the two variables. Table 6 presents the cross-tabulation table for geopolitical zone and HCT uptake. The participants from the northcentral zone were the most likely to have HCT uptake, followed respectively by participants from the southeast zone, southwest zone, northeast zone, and northwest zone.

Results of the multivariate binomial logistic regression, testing for all IVs as predictors of HCT uptake indicated that the variables of gender, place of residence, education, geopolitical zone, knowledge of where to obtain HCT, and knowledge of HIV transmission were statistically significant predictors of the likelihood of having HCT uptake. Table 7 represents the chi-square test for geopolitical zone and HCT uptake.

The results of the chi-square test of association between geopolitical zone and HCT uptake showed that there is a statistically significant relationship between geopolitical zone and HCT uptake among young people ages 15 to 24 years in Nigeria, $X^{2}(5, N=8920)=186.40, p<0.001$.

\subsection{Discussion of Results}

The demographic variables of gender, place of residence, level of education, geopolitical zone, and SES were found to be significantly associated with HCT uptake in the sample. A discussion of each demographic factor follows.

Gender. The study found that the female participants had a small but significantly higher incidence of HCT uptake than the male participants did. Potential reasons are that HIV generally has longer lasting and more severe effects on women than on men and because women are more conscious and aware of their sexual health status [2]. Women have a higher knowledge of where to obtain HCT services and were more likely to use HCT services than men [17]. However, HIV is equally serious and equally deadly for men and women. The implication 
Table 6. Cross-Tab test for geopolitical zone and HCT uptake.

\begin{tabular}{|c|c|c|c|c|c|c|c|c|c|}
\hline & & & \multicolumn{6}{|c|}{ Geopolitical zone } & \multirow{2}{*}{ Total } \\
\hline & & & North-central & North-east & North-west & South-east & South-south & South-west & \\
\hline \multirow{4}{*}{$\begin{array}{c}\text { HCT } \\
\text { uptake }\end{array}$} & \multirow[b]{2}{*}{ No } & Count & 1172 & 1126 & 1374 & 1112 & 1273 & 1025 & 7082 \\
\hline & & $\begin{array}{c}\text { \% within } \\
\text { geopolitical zone }\end{array}$ & $71.4 \%$ & $83.7 \%$ & $89.6 \%$ & $77.1 \%$ & $78.1 \%$ & $77.3 \%$ & $79.4 \%$ \\
\hline & \multirow[b]{2}{*}{ Yes } & Count & 469 & 219 & 160 & 331 & 358 & 301 & 1838 \\
\hline & & $\begin{array}{c}\text { \% within } \\
\text { geopolitical zone }\end{array}$ & $28.6 \%$ & $16.3 \%$ & $10.4 \%$ & $22.9 \%$ & $21.9 \%$ & $22.7 \%$ & $20.6 \%$ \\
\hline \multirow{2}{*}{\multicolumn{2}{|c|}{ Total }} & Count & 1641 & 1345 & 1534 & 1443 & 1631 & 1326 & 8920 \\
\hline & & $\begin{array}{c}\text { \% within } \\
\text { geopolitical zone }\end{array}$ & $100.0 \%$ & $100 \%$ & $100 \%$ & $100 \%$ & $100 \%$ & $100 \%$ & $100 \%$ \\
\hline
\end{tabular}

Table 7. Chi-Square test for geopolitical zone and HCT uptake.

\begin{tabular}{cccc}
\hline & Value & $\boldsymbol{d f}$ & Asymp. Sig. (2-sided) \\
Pearson chi-square & 186.395 & 5 & 0.000 \\
Likelihood ratio & 198.439 & 5 & 0.000 \\
Linear-by-linear association & 0.430 & 1 & 0.512 \\
No. of valid cases & 8920 & & \\
\hline
\end{tabular}

of this result to my study is that although there is a significant need for HCT uptake by both genders, the need is even greater for men.

Place of Residence. Place of residence, that is, urban versus rural, was associated with the participants' HCT uptake, with the incidence of HCT uptake being lower for participants from rural areas. This result might reflect the relative lack of HCT facilities in rural settings or the cognitive differences (discussed in the next section) between urban and rural populations. Various researchers have confirmed greater use of HCT facilities when individuals live in close proximity to such facilities, as they generally would in urban settings [1] [18]-[20].

Level of Education. The study found level of education to be positively associated with HCT uptake; the higher the level of education, the greater was the use of HCT resources. This result supports earlier findings that a constant and linear relationship exists between level of education and HCT uptake [6] [21] [22].

Geopolitical Zone. It was found that although geopolitical zone did have a significant relationship with HCT uptake, no pattern emerged other than the urban versus rural difference. Although differences existed in the different geographical areas of Nigeria in terms of HCT uptake rates, they did not suggest any particular actions or interventions. It could be, as suggested earlier, that proximity to HCT facilities is the most important factor in HCT uptake.

SES. The study found that SES had a significant relationship with HCT uptake. Participants with a higher SES had higher HCT uptake rates. Several researchers identified a positive correlation between university attendance and HCT uptake [18] [23] [24]. Because university students in Nigeria tend to be more affluent than other urban dwellers, or come from families that are, and urban dwellers tend to be more affluent than rural residents, this fact reinforces other findings of the study.

\section{Conclusion}

The results showed that significant relationships exist among various sociodemographic factors (gender, place of residence, level of education, geopolitical zone, and SES) among young people in Nigeria. The quantitative measures used provided statistical and objective justifications of the relationships between and among the variables.

\section{Recommendations}

Although some variables can be controlled, such as level of education, knowledge of HIV transmission, and 
knowledge of HIV prevention, other variables cannot. The study therefore recommends that the goal of future researchers should be to examine the effect of the variables that can be controlled.

Again, examining the efficacy of HCT treatments in Nigeria, along with conducting a demographic analysis of the at-risk population, could be beneficial in informing the authorities who are responsible for allocating finite medical resources.

Religion and cultural norms should serve as a vehicle for preventing stigmatization and other related factors which often negatively affect the use of HCT resources by the Nigerian population.

Lastly, since lack of education can contribute negatively in the spread of HIV especially among young people in Nigeria, it is therefore recommended that young people in the country should be better educated about HIV awareness, transmission and prevention.

\section{Funding}

No funding was received for this study.

\section{Conflict of Interest}

I declare that I have no conflict of interest.

\section{Ethical Approval}

This article does not contain any studies with human participants performed by any of the authors.

\section{References}

[1] Mbamara, S.U. and Obiechina, N.J. (2013) Awareness and Attitudes toward Voluntary Counseling and Testing for HIV/AIDS among Law Undergraduates in Tertiary Institutions in Southeast Nigeria. Journal of Reproductive Medicine, 58, 55-60.

[2] Oladunni, T.M. and Osezua, C. (2013) Acceptance and Uptake of HIV Counseling and Testing by Youth Corp Members in Osun State, Nigeria. International Journal of Asian Social Science, 3, 1381-1388.

[3] Obidoa, C.A., M’Lan, C.E. and Schensul, S.L. (2012) Factors Associated with HIV/AIDS Sexual Risk among Young Women Aged 15 - 24 Years in Nigeria. Journal of Public Health in Africa, 3, e15. http://dx.doi.org/10.4081/jphia.2012.e15

[4] Azuogu, B., Ogbonnaya, L. and Alo, C. (2011) HIV Voluntary Counseling and Testing Practices among Military Personnel and Civilian Residents in a Military Cantonment in Southeastern Nigeria. HIV AIDS (Auckland), 3, 107-116.

[5] Adekeye, O.A. (2009) HIV Voluntary Counselling and Testing for Young People: The Antidote for a Healthy and Positive Living in Nigeria. Counsellor, 26, 13-26.

[6] Ibrahim, M., Ipadeola, O., Adebayo, S. and Fatusi, A. (2013) Socio-Demographic Determinants of HIV Counseling and Testing Uptake among Young People in Nigeria. International Journal of Prevention and Treatment, 2, 23-31.

[7] Akhigbe, R.E. and Bamidele, J.O. (2013) Prevalence and Pattern of Utilization of Voluntary Counseling and Testing Services and HIV Infection in Ogbomoso, Southwestern Nigeria. Journal of Natural Science, Biology and Medicine, 4, 163-166. http://dx.doi.org/10.4103/0976-9668.107283

[8] Nwachukwu, C.E. and Odimegwu, C. (2011) Regional Patterns and Correlates of HIV Voluntary Counselling and Testing among Youths in Nigeria. African Journal of Reproductive Health, 15, 131-146.

[9] Osazuwa, F., Dirisu, J.O. and Okuonghae, P.E. (2012) Early Determination of Human Immunodeficiency Virus Status by Routine Voluntary Counseling and Testing in Benin City, Nigeria. North American Journal of Medical Sciences, 4, 99-103. http://dx.doi.org/10.4103/1947-2714.93378

[10] Thompson, O., Ipadeola, O. and Makinde, O.N. (2013) Knowledge, Perception and Acceptance of Couple HIV Counselling and Testing in a Rural Community in Nigeria. Public Health Research, 3, 85-91.

[11] United Nations Population Fund (2013) Priority Areas of Support and Key Achievements/Contributions to Nigeria's HIV/AIDS Response. http://nigeria.unfpa.org/

[12] National Bureau of Statistics (2010) The National Literacy Survey. http://www.nigerianstat.gov.ng/

[13] World Health Organization (2015) Gender, Women and Health. http://www.who.int/

[14] Federal Ministry of Health (2013) National HIV \& AIDS and Reproductive Health Survey, 2012 (NARHS Plus). Author, Abuja. 
[15] Ajuwon, A.J., Titiloye, M., Oshiname, F. and Oyewole, O. (2011) Knowledge and Use of HIV Counseling and Testing Services among Young Persons in Ibadan, Nigeria. International Quarterly of Community Health Education, 31, 3350. http://dx.doi.org/10.2190/IQ.31.1.d

[16] Creswell, J.W. (2009) Research Design: Qualitative, Quantitative, and Mixed Methods Approaches. SAGE, Thousand Oaks.

[17] Ogaji, D.S., Oyeyemi, A.S. and Ibrahim, I. (2014) Awareness, Willingness and Use of Voluntary HIV Testing and Counseling Services by Students of a University in South-South Nigeria. Journal of Community Medicine and Primary Health Care, 25, 36-44.

[18] Iliyasu, Z., Isa, S., Mohammed, A. and Aliyu, M. (2006) Knowledge of HIV/AIDS and Attitude towards Voluntary Counseling and Testing among Adults. Journal of National Medical Association, 98, 1917-1922.

[19] Mall, S., Middelkoop, K., Mark, D., Wood, R. and Bekker, L. (2013) Changing Patterns in HIV/AIDS Stigma and Uptake of Voluntary Counselling and Testing Services: The Results of Two Consecutive Community Surveys Conducted in the Western Cape, South Africa. AIDS Care, 25, 194-201. http://dx.doi.org/10.1080/09540121.2012.689810

[20] Kalichman, S. and Simbayi, L. (2003) HIV Testing Attitudes, AIDS Stigma, and Voluntary HIV Counselling and Testing in a Black Township in Cape Town, South Africa. Sexually Transmitted Infections, 79, 442-447. http://dx.doi.org/10.1136/sti.79.6.442

[21] Oginni, A., Obianwu, O. and Adebajo, S. (2014) Socio-Demographic Factors Associated with Uptake of HIV Counseling and Testing (HCT) among Nigerian Youth. AIDS Research and Human Retroviruses, 30, A113-A113. http://dx.doi.org/10.1089/aid.2014.5216.abstract

[22] Uzochukwu, B., Uguru, N., Ezeoke, U., Onwujekwe, O. and Sibeudu, T. (2011) Voluntary Counseling and Testing (VCT) for HIV/AIDS: A Study of the Knowledge, Awareness and Willingness to Pay for VCT among Students in Tertiary Institutions in Enugu State Nigeria. Health Policy, 99, 277-284. http://dx.doi.org/10.1016/j.healthpol.2010.11.007

[23] Mgosha, P.C., Eliningaya, J.K., Aneth, M.M., Longin, R. and Mahande, M.J. (2009) Evaluation of Uptake and Attitude to Voluntary Counseling and Testing among Health Care Professional Students in Kilimanjaro Region, Tanzania. BMC Public Health, 9, 1-9.

[24] Odimegwu, C., Adedeni, S.A. and Ononokpono, D.N. (2013) HIV/AIDS Stigma and Utilization of Voluntary Counselling and Testing in Nigeria. BMC Public Health, 13, 1-14. http://dx.doi.org/10.1186/1471-2458-13-465 